Article

\title{
The Putative Histone Methyltransferase DOT1 Regulates Aflatoxin and Pathogenicity Attributes in Aspergillus flavus
}

\author{
Linlin Liang ${ }^{\dagger}$, Yinghang Liu ${ }^{\dagger}$, Kunlong Yang ${ }^{\dagger}$, Guinan Lin, Zhangling Xu, Huahui Lan, \\ Xiuna Wang and Shihua Wang * \\ Fujian Key Laboratory of Pathogenic Fungi and Mycotoxins, Key Laboratory of Biopesticide and Chemical \\ Biology of Education Ministry, and School of Life Sciences, Fujian Agriculture and Forestry University, \\ Fuzhou 350002, China; 1llyiyuan@sina.com (L.L.); lyinghang35324@163.com (Y.L.); ykl_long@yeah.net (K.Y.); \\ linguinan1996@outlook.com (G.L.); xuzhangling0409@163.com (Z.X.); huahuilan90@sina.com (H.L.); \\ Wangxn@cau.edu.cn (X.W.) \\ * Correspondence: wshyyl@sina.com; Tel./Fax: +86-591-8798-4471 \\ + These authors contributed to this work equally.
}

Academic Editor: Shohei Sakuda

Received: 4 July 2017; Accepted: 20 July 2017; Published: 24 July 2017

\begin{abstract}
Lysine methyltransferases transfer methyl groups in specific lysine sites, which regulates a variety of important biological processes in eukaryotes. In this study, we characterized a novel homolog of the yeast methyltransferase DOT1 in A. flavus, and observed the roles of dot1 in A. flavus. Deletion of dot 1 showed a significant decrease in conidiation, but an increase in sclerotia formation. A change in viability to multiple stresses was also found in the $\Delta$ dot 1 mutant. Additionally, aflatoxin (AF) production was found severely impaired in the $\Delta$ dot 1 mutant. Further analysis by qRT-PCR revealed that the transcription of AF structural genes and their regulator gene aflS were prominently suppressed in the $\Delta d o t 1$ mutant. Furthermore, our data revealed that Dot1 is important for colonizing maize seeds in A. flavus. Our research indicates that Dot1 is involved in fungal development, aflatoxin biosynthesis and fungal virulence in A. flavus, which might provide a potential target for controlling A. flavus with new strategies.
\end{abstract}

Keywords: histone methylation; sclerotia; stress response; fungal virulence

\section{Introduction}

The ubiquitous fungus $A$. flavus is notorious for its contamination of many foodstuffs and important crops, such as maize, peanuts and rice, during pre- or post-harvest with the most carcinogenic mycotoxin, aflatoxin [1-3]. This fungus is also known as the second most frequent Aspergillus pathogen after A. fumigatus on immunosuppressed patients, which is also responsible for aspergillosis diseases or liver cancer for human and animals caused by the consumption of contaminated food $[1,2,4]$. Due to this, this fungus has caused enormous agricultural economic losses, food shortages and health problems all cross the world [1,5]. Thus, effective measures to restrict this pathogen are urgently needed, not only to protect human and animal health, but also to alleviate its deleterious effects on agricultural economic losses.

It is quite important to develop rational control strategies for $A$. flavus underlying the fungal virulence and mycotoxins attributes. Although numerous studies reported that pathogenesis in A. flavus was connected with fungal development, secondary metabolism and the adaptability to environmental factors $[1,6-8]$, much remains to be learned about the fungal pathogenesis. In the past decade, histone posttranslational modifications (HPTMs), such as phosphorylation, ubiquitination, 
SUMOylation, acetylation and methylation, have been well documented as providing an important link between many biological processes, fungal secondary metabolite biosynthesis and chromatin-based regulation in eukaryotic cells [5,9-11]. Among these, histone methylation was one of most thoroughly studied epigenetic process in HPTMs. In particular, it has been shown that histone lysine methylation catalyzed by lysine methyltransferases in histone specific lysine sites, such as H3K4me2/3, is associated with active regions of chromatin, and $\mathrm{H} 3 \mathrm{~K} 9 \mathrm{me} 2 / 3$ and $\mathrm{H} 3 \mathrm{~K} 27 \mathrm{me} 2 / 3$ are related to repressive regions [12-15]. In Neurospora crassa, DIM-5, responsible for H3K9 methylation, has a close relationship with gene silencing by mediating DNA methylation on particular cytosine sites [16,17]. The H3K36 methyltransferase SET-2 in N. crassa has also been reported to regulate fungal development $[16,18]$. H3K4me and H3K27me are addressed as important for fungal development and many secondary metabolites biosynthesize in fungi $[9,12]$.

Studies have demonstrated that many gene clusters of secondary metabolites, including the AF gene cluster, are located near telomeres in Aspergillus flavus [19,20]. Genes near telomeres, associated with specific chromatin structures, have position effects, resulting in gene silencing $[19,21]$. HPTMs such as acetylation, methylation, and ubiquitination have been linked to transcriptional silencing. The inactivation of H3K79 methylation or H3K4 methylation is quite important for heterochromatin formation and for maintaining silencing regions of chromatin in budding yeast [21-23]. An abnormal expression of the H3K79 methyltransferase gene dot 1 in yeast and mammalian cells leads to a decrease of gene silence [23,24]. In Aspergillus, although many studies have been shown that HPTMs regulate fungal development and secondary metabolite biosynthesis [9,10,25-27], there has been little progress in addressing the function of histone lysine methylation in A. flavus. Here, in order to know if H3K79 is involved in AF biosynthesis, we identified a putative H3K79 methyltransferase Dot1 in A. flavus, and then observed the potential roles of the dot 1 gene in A. flavus by addressing the effects of the deletion mutant on the development, conidiation, sclerotia formation, aflatoxin biosynthesis, and pathogenicity of seeds.

\section{Results}

\subsection{Characterization of Histone H3K79 Methyltransferase in A. flavus}

To characterize the homolog of the S. cerevisiae H3K79 methyltransferase Dot1 in A. flavus, we used BlastP analyses in the NCBI (https:/ / blast.ncbi.nlm.nih.gov / Blast.cgi?PAGE=Proteins) with the amino acid sequence of S. cerevisiae Dot1 (EGA79271.1) as queries. AFLA_093140, encoding a 503 aa protein, was identified in A. flavus, which shared a 33\% overall identity with S. cerevisiae Dot1. The Dot1 protein sequences from different fungi were downloaded, and analyzed their evolutionary relationship by MEGA5.0, which showed that Dot1 from Aspergillus Dot1 was highly conserved (Figure 1A). Dot1 from Aspergillus has two exons, and the locations and paralogs of dot1 were also quite conserved in the Aspergillus genomes (Figure 1C). The alignment of Dot1 protein sequences from different fungal species indicates that H3K79 methyltransferase only possesses the DOT1 domain (Figure 1B), however, in Homo sapiens the H3K79 methyltransferase has another domain AT_hook, which is a DNA-binding motif with a preference for A/T rich regions (Figure 1B).

\subsection{Construction of the Deleted ( $\Delta$ dot 1$)$ and Complemented $\left(\operatorname{dot} 1^{C}\right)$ Mutant Strains}

The $\Delta$ dot 1 mutants were generated using a homologous recombination strategy as shown in Figure 2A. The selected transformants of $\Delta$ dot 1 were analyzed by diagnostic PCR (Figure 2B), and the results showed that a $0.5 \mathrm{~kb}$ ORF fragment was amplified from $\mathrm{WT}$, but none from $\Delta$ dot1 (Figure 2B). With gDNA as a template, both $2.0 \mathrm{~kb}$ AP and $2.1 \mathrm{~kb}$ BP fragments were amplified in $\Delta$ dot 1 mutant, but not in wild type (WT) (Figure 2B). The $\Delta$ dot1 mutant then was further confirmed by southern blot analyses (Figure 2C). To confirm that the phenotype changes observed in $\Delta$ dot 1 were due to the disruption of $\operatorname{dot} 1$, the $\Delta$ dot 1 mutant was complemented with a full-length of $\operatorname{dot} 1$ by a pPTRI plasmid and fused into the $\Delta$ dot 1 protoplast. The $\operatorname{dot}^{C}$ complemented strains were also confirmed by 
diagnostic PCR using the genomic DNA (Figure 2B) and further verified by RT-PCR, and the result showed that transcription level of $\Delta$ dot1 was not detected in $\Delta$ dot1, in contrast to the wild type (WT) and $\operatorname{dot}^{C}$ strains (Figure 2D). All these results indicated that the deletion $\Delta \operatorname{dot} 1$ and complemented $\operatorname{dot}^{C}$ mutant strains were successfully constructed.

A.

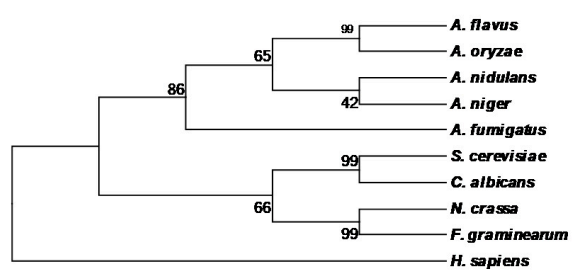

C. 1041045517010 A_flavus_NRRL_3557/+ (2040265 bp)

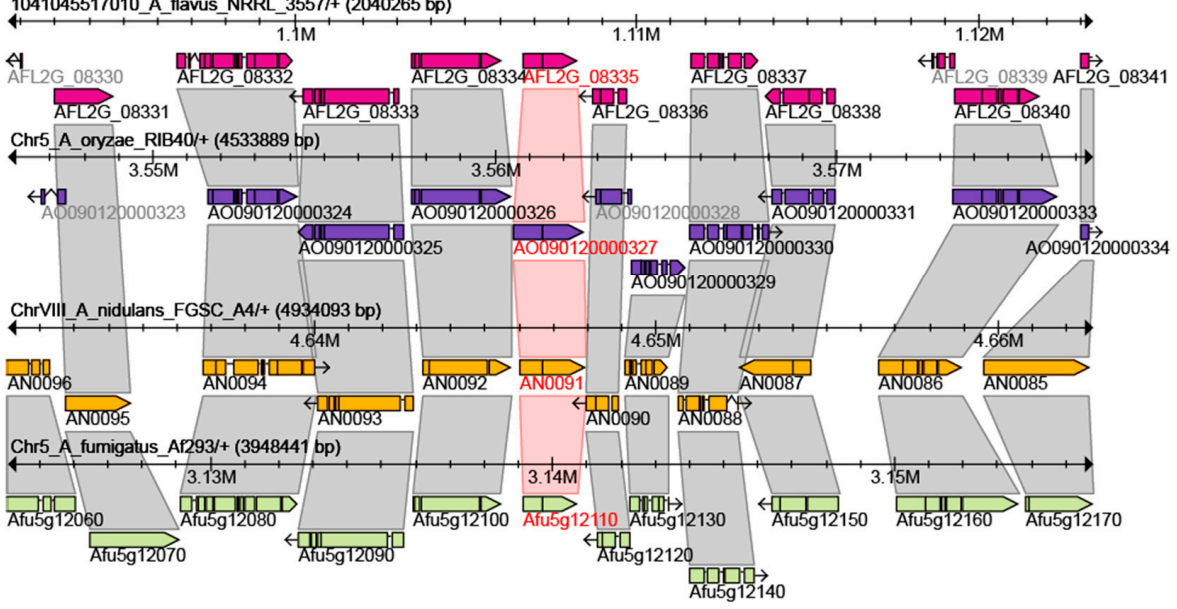

Figure 1. Characterization of H3K79 methyltransferase in A. flavus. (A) Phylogenetic relationship of Dot1 from different species was analyzed; (B) Domains from Dot1 proteins were characterized by SMART, and software DOG 2.0 were used to visualize protein domains; (C) The locations and paralogs of dot1 in Aspergillus genomes were analyzed by AspGD (http://www.aspgd.org/).

A.

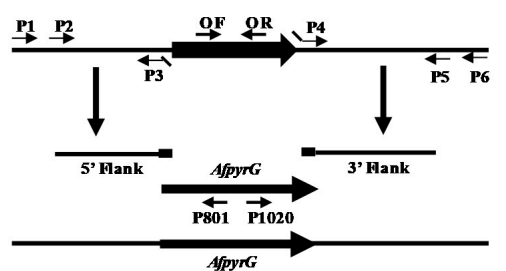

C.

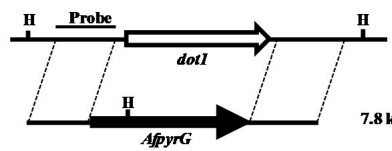

B.

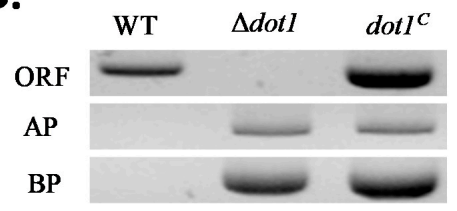

D.

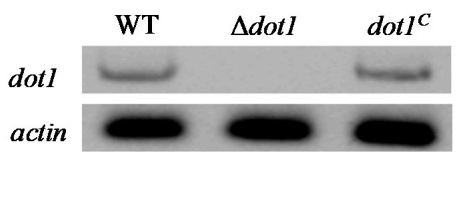

Figure 2. Deletion strategy and confirmation of the mutant strains. (A) Deletion strategy for $\Delta$ dot1 using homologous recombination; (B) Deleted $\Delta \operatorname{dot} 1$ and complemented $\operatorname{dot}_{1}{ }^{C}$ strains were tested by PCR analysis with genomic DNA as template; (C) Southern blot analyses of dot1 deletion mutants using PCR fragment of $5^{\prime}$ flanking region as probes. Genomic DNAs were extracted from WT and putative transformants. Restriction was carried out using the indicated enzymes; (D) $\Delta \operatorname{dot} 1$ and $\operatorname{dot}_{1} \mathrm{C}$ mutant strains were tested by RT-PCR with cDNA as template. 


\subsection{Dot1 Is Involved in Fungal Growth and Sporulation}

To know the potential role of the H3K79 methyltransferase gene dot1 in fungal development in A. flavus, the $\triangle \operatorname{dot} 1, \mathrm{WT}$ and $\operatorname{dot}^{\mathrm{C}}$ strains were inoculated on YES and PDA in the dark at $37^{\circ} \mathrm{C}$, and the results showed that the $\Delta$ dot1 mutant displayed less pigmentation and marginally decreased in radial growth compared to $d o t 1^{C}$ or WT strains (Figure $\left.3 \mathrm{~A}, \mathrm{~B}\right)$. The $\Delta$ dot 1 mutant also displayed a significant decrease in conidiation compared to the WT or $\operatorname{dot}^{C}$ strain $(p<0.01)$ (Figure 3D). Further examination in sporogenesis also showed that the $\Delta$ dot 1 mutant produced less normal conidiophore compared to the WT and $\operatorname{dot}^{C}{ }^{C}$ strain (Figure 3C). qRT-PCR was performed to detect the transcriptional expression levels of the conidia transcriptional factors genes $b r l A$ and $a b a A$, which showed that the transcriptional levels of these two conidia specifie genes were both down-regulated in the $\Delta$ dot1 mutant (Figure 3E). These results demonstrate that Dot1 contributes to radical growth and conidiation in A. flavus.

A.

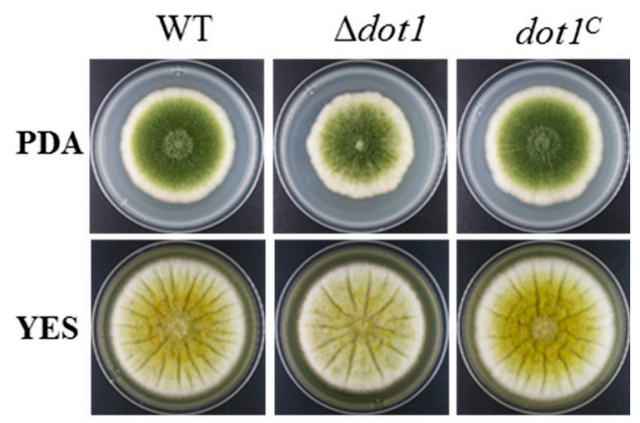

B.

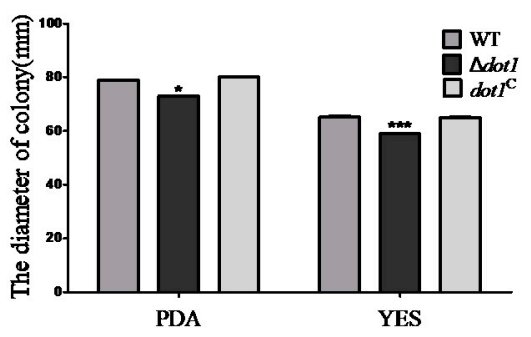

D.

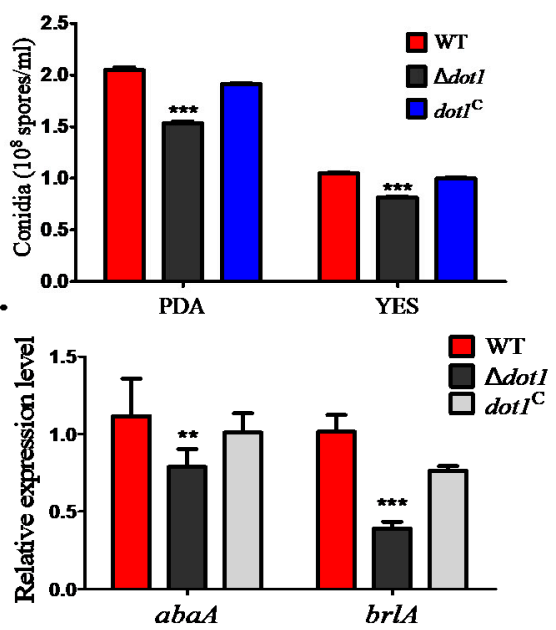

C.

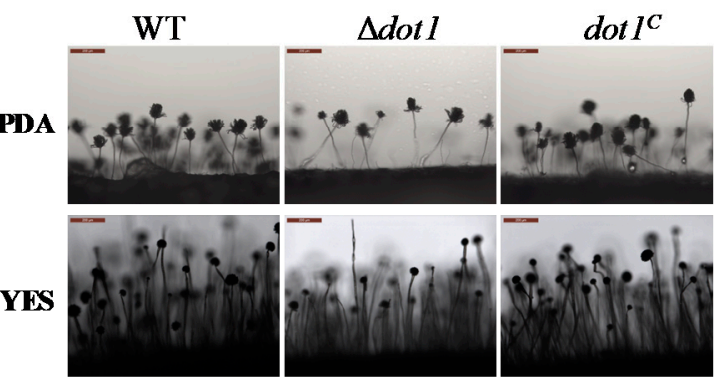

E.

Figure 3. The $\Delta$ dot1 mutant was altered in vegetative growth and conidiation. (A) Phenotype of the WT, $\Delta \operatorname{dot} 1$ and $\operatorname{dot} 1^{\mathrm{C}}$ strains after grown on PDA and YES agar plates at $37^{\circ} \mathrm{C}$ for 4 days; (B) colony diameter in on PDA and YES cultures of the WT strain and mutants were assayed; (C) Conidiophores was detected by microscope after light induction; (D) The amount of conidia from different strains were determined; (E) Transcriptional levels of conidia transcriptional factors genes in the $\Delta$ dot 1 mutant, WT and $\operatorname{dot}^{C}{ }^{C}$ strains. ${ }^{*}, * *$ and ${ }^{* * *}$ represent significantly different $(p \leq 0.05, p \leq 0.01$ or $p \leq 0.001$, respectively). The experiments were conducted with technical triplicates for each strain, and were repeated three times.

\subsection{Dot1 Plays a Negative Role in Sclerotial Reproduction in A. flavus}

Sclerotia is considered to be a vestige of the cleistothecia, which is a survival structure for A.flavus to live through a stress environment. To determine if Dot1 participated in sclerotia formation, the $\Delta d o t 1$ mutant was cultured on WKM agar. The $\Delta$ dot1 mutant was found to produce a larger amount of sclerotia $(207 \pm 1.73)$ than WT $(150.67 \pm 0.88)$ and the $\operatorname{dot}^{C}{ }^{C}$ strain $(152.67 \pm 2.27)(p<0.001)$ (Figure 4A,B). The qRT-PCR was performed to confirm the expressing levels of genes that were reported to be related with sclerotia formation, which indicated that $n s d C, n s d D$ and $s c l R$ were all 
transcriptionally up-regulated in the $\Delta$ dot1 mutant (Figure 4C), demonstrating that Dot1 negatively regulated sclerotia formation in A. flavus.

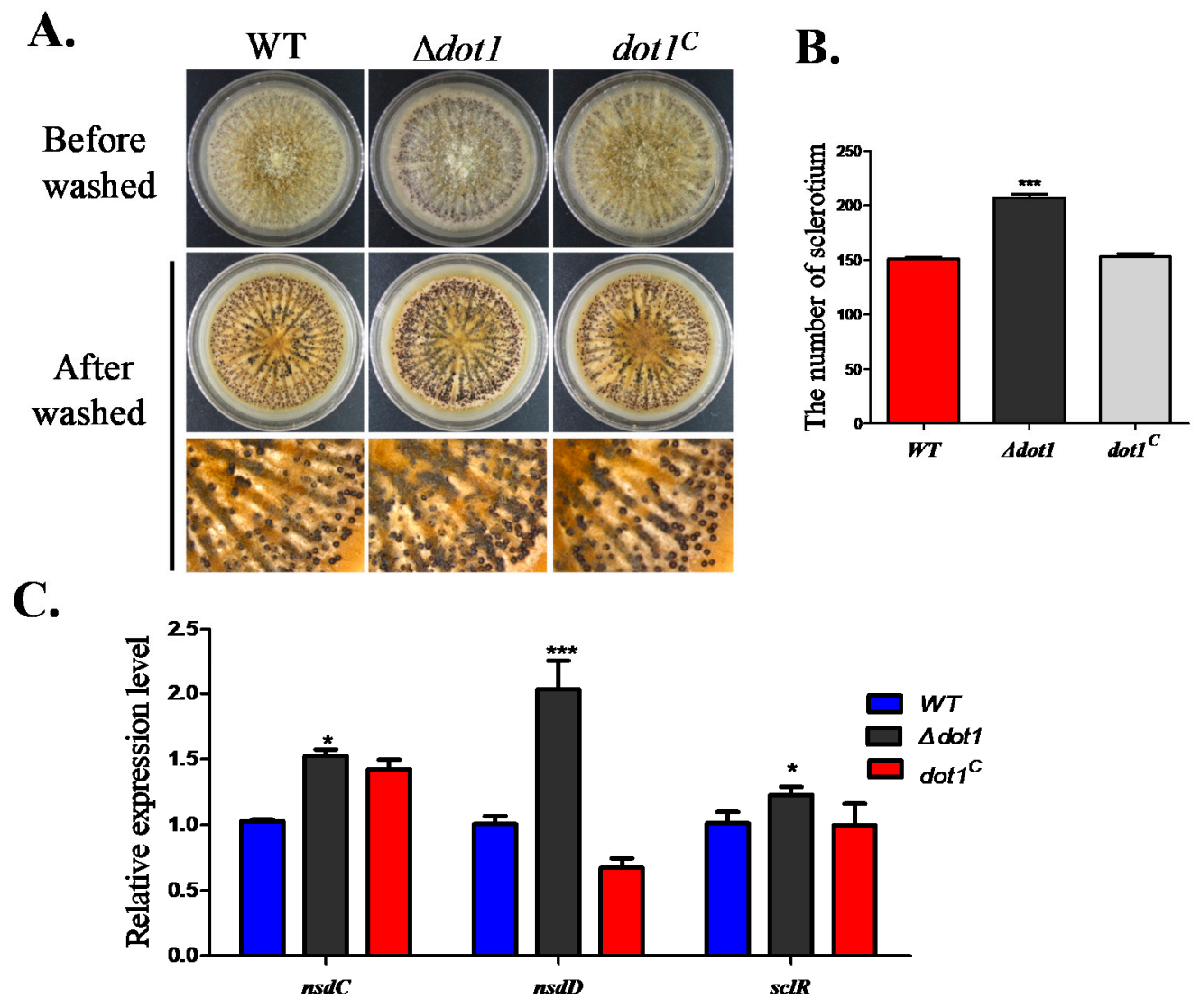

Figure 4. Sclerotia reproduction analysis among the WT, $\Delta \operatorname{dot} 1$ and $\operatorname{dot}^{\mathrm{C}} \mathrm{strains}$. (A) Phenotype of the $\mathrm{WT}, \Delta \operatorname{dot} 1$ and $\operatorname{dot}^{\mathrm{C}}$ strains were determined after being grown on sclerotia-inducing media, Wickerham medium. The plates were sprayed with $70 \%$ ethanol to allow visualization of sclerotia; (B) The amount of sclerotia was measured in (A); (C) Transcriptional levels of the sclerotial specific gene $n s d C, n s d D$ and $s c l R$. * and ${ }^{* * *}$ represent $p \leq 0.05$ and $p \leq 0.001$, respectively. The experiments were performed with four biological replicates for each strain, and were repeated three times.

\subsection{Dot1 Response to Multiple Stresses in A. flavus}

Histone post-translational modifications have been shown to contribute to DNA damage repair [28]. To determine the viability of dot 1 in response to genotoxicity stress, the strains were cultured on a PDA medium within $0.02 \%$ methylmercuric sulfate (MMS) or $15 \mathrm{mM}$ hydroxyurea (HU) for $3 \mathrm{~d}$. As shown in Figure $5 \mathrm{~A}, \mathrm{~B}$, the $\Delta$ dot1 mutant showed less sensitivity to genotoxicity stress than the WT and $\operatorname{dot}_{1}{ }^{C}$ strain. Since the $\Delta \operatorname{dot} 1$ mutant showed increased resistance to genotoxicity stress, we were also interested in addressing whether Dot1 responsed to other stresses. As we can see in Figure 5C,D, the WT and $\operatorname{dot}^{C}{ }^{C}$ strains, but not $\Delta$ dot1, were much more sensitive to the cell-wall-damaging agent SDS (sodium dodecyl sulfate) and oxidative agent tBooH (tert-butyl hydroperoxide). All these results demonstrated that Dot1 has a potential role in response to multiple stresses in A. flavus. 


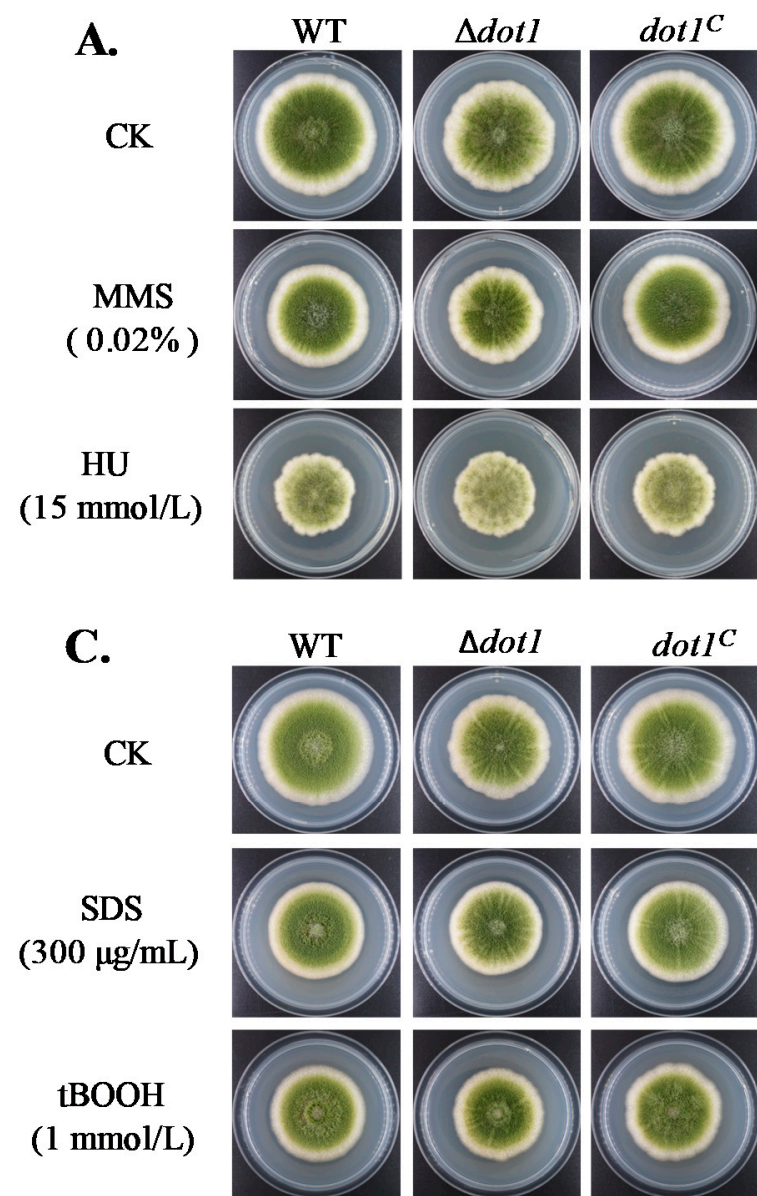

B.
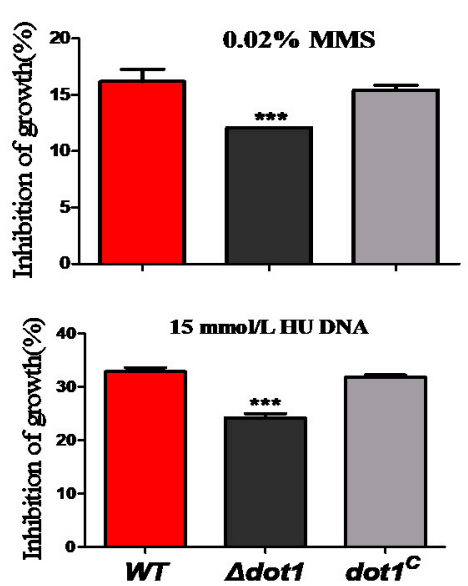

D.

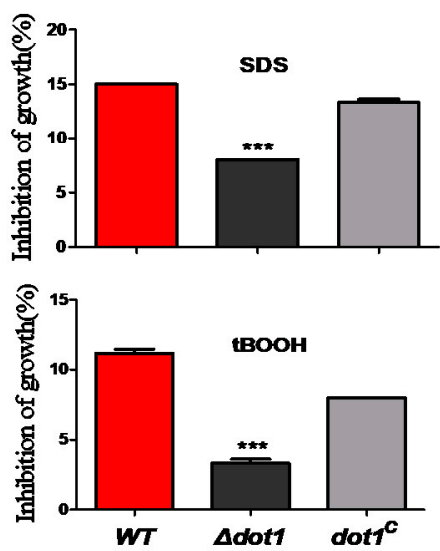

Figure 5. Growth of the WT, $\operatorname{dot} 1$ and $\operatorname{dot} 1^{C}$ strains under multiple stresses. (A) Phenotype of WT, $\Delta \operatorname{dot} 1$ and $\operatorname{dot}^{C}$ strains when incubated within $0.02 \%$ methylmercuric sulfate (MMS) or $15 \mathrm{mM}$ hydroxyurea (HU) for $3 \mathrm{~d}$; (B) The growth inhibition rate of $\mathrm{WT}, \Delta \operatorname{dot} 1$ and $\operatorname{dot} 1^{\mathrm{C}}$ strains under genome integrity stress. The inhibition rate of growth was relative to the growth rate of each untreated strain, Inhibition of growth rate $=\frac{\text { (the diameter of untreated strain-the diameter of treated strain) }}{\text { the diameter of untreated strain }} \times 100 \%$; (C) Morphology of WT, $\Delta \operatorname{dot} 1$ and $\operatorname{dot}^{C}{ }^{C}$ strains when incubated within $300 \mu \mathrm{g} / \mathrm{mL}$ SDS or $1 \mathrm{mmol} / \mathrm{L}$ tBooH; (D) The growth inhibition was quantified in (C). ${ }^{* *}$ represent significantly different $p \leq 0.001$. The experiments were performed with four biological replicates for each strain, and were repeated three times.

\subsection{Dot1 Contributes to Aflatoxin Biosynthesis}

A previous study showed that histone methylation is involved in secondary metabolite synthesis in many Aspergillus species [9]. Thus, we detected aflatoxin production-which is the most important secondary metabolite in A. flavus - in PDA agar media after being cultured for $5 \mathrm{~d}$ at $29^{\circ} \mathrm{C}$. The TLC results indicated that AF production was severely impaired in the $\Delta d o t 1$ mutant (Figure $6 \mathrm{~A}, \mathrm{~B}$ ). The result was further confirmed by HPLC analysis, which also showed a significant decrease in AFB1 production, as well as $\mathrm{AFB}_{2}$ production in the $\Delta d o t 1$ mutant (Figure $6 \mathrm{C}$ ). The transcript levels of the AF-regulated genes(aflR and aflS) and the biosynthesis genes (aflC and aflO) in the $\triangle$ dot1 mutant were determined by qRT-PCR, which demonstrated that aflS, aflC and aflO, but not aflR, were transcriptionally inhibited in the $\Delta d o t 1$ mutant (Figure 6D). All these results indicated that Dot1 might be involved in regulating aflatoxin biosynthesis in A. flavus. 
A.

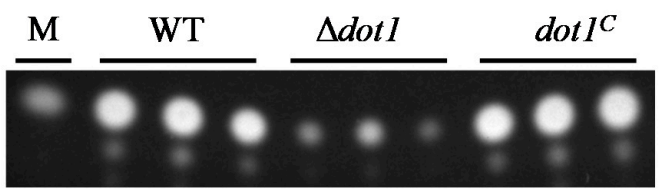

B.

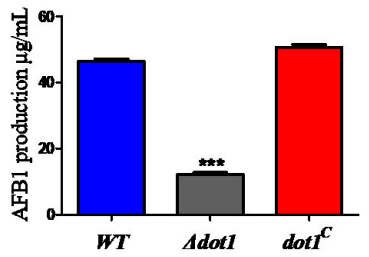

C.

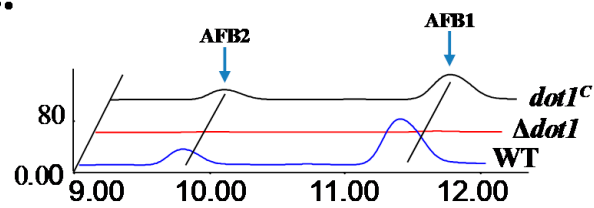

D.

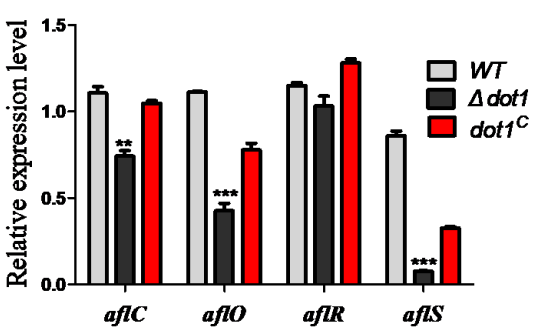

Figure 6. AF production of the $\mathrm{WT}, \operatorname{dot} 1$ and $d o t 1^{C}$ strains. (A) AF production was measured by Thin-Layer Chromatography (TLC) after being grown on PDA medium for $5 \mathrm{~d}$ at $29^{\circ} \mathrm{C}$ in the dark. (B) Relative AF production in (A) was qualified. (C) HPLC analysis of aflatoxin produced by the WT, $\Delta \operatorname{dot} 1$ and $\operatorname{dot} 1^{\mathrm{C}}$ strains after being grown on PDA medium for $5 \mathrm{~d}$ at $29^{\circ} \mathrm{C}$. (D) Transcriptional level of the AF-related genes aflR, aflS, aflC $(p k s A)$ and aflO(omtB) from WT, $\Delta \operatorname{dot} 1$ and $\operatorname{dot}^{\mathrm{C}}{ }^{\mathrm{C}}$ strains. * and ${ }^{* * *}$ represent $p \leq 0.05$ and $p \leq 0.001$, respectively. The experiments were performed with three biological replicates for each strain, and were repeated three times.

\subsection{Dot1 Contributes to t Crop Seeds Colonization}

A. flavus is notorious for its contamination of many important crops and plant seeds with aflatoxins. To assay the role of Dot1 in pathogenicity, maize corn seeds were inoculated with spore suspension from WT, $\Delta d o t 1$ and $\operatorname{dot}^{\mathrm{C}}{ }^{\mathrm{C}}$ strains. The $\Delta d o t 1$ mutant showed a reduced ability to colonize maize seeds (Figure 7A), which also exhibited a significant drop in conidia production (Figure 7B). Mycotoxin production from the infected maize seeds was also detected, which showed that AF production was blocked in the $\Delta$ dot1 mutant (Figure 7C). These data suggested that Dot1 was important for colonizing maize seeds.

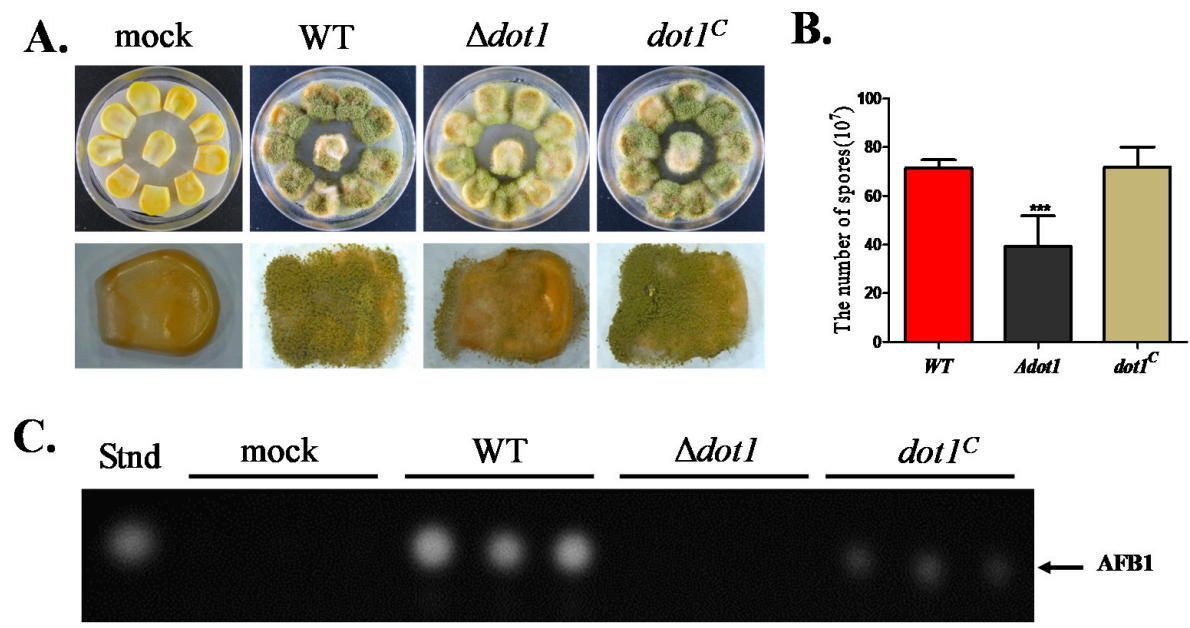

Figure 7. Seed infection of the WT, $\Delta \operatorname{dot} 1$ and $\operatorname{dot} 1^{C}$ strains. (A) Phenotype of fungal strains grown on living maize corn seeds; (B) The amount of conidia was determined from the infected seeds; (C) Mycotoxin production from infected maize corn seed was detected by TLC. ${ }^{* * *}$ represents $p \leq 0.001$. The experiments were performed with five biological replicates for each strain, and were repeated three times. 


\subsection{Subcellular Localization of Dot1 in A. flavus}

In order to determine the localization pattern of Dot1, we constructed an eGFP tag with a 5 Gly-Ala linker, and inserted the tag at the C-terminus of the Dot1 protein (Figure 8A). AfpyrG was used as the selective marker to screen the Dot1::eGFP transformants, which displayed no phenotype difference with the WT strain (data not shown), suggesting that Dot1-eGFP was fully functional. In the hyphae growth period, Dot1-eGFP was found to be mainly accumulated in the nucleus (Figure 8B), which was verified by 40,6-diamidino-2-phenylindole (DAPI) stain, while no green fluorescence signal was found in the WT strain. All these results showed that Dot1 mainly functions in the nucleus.
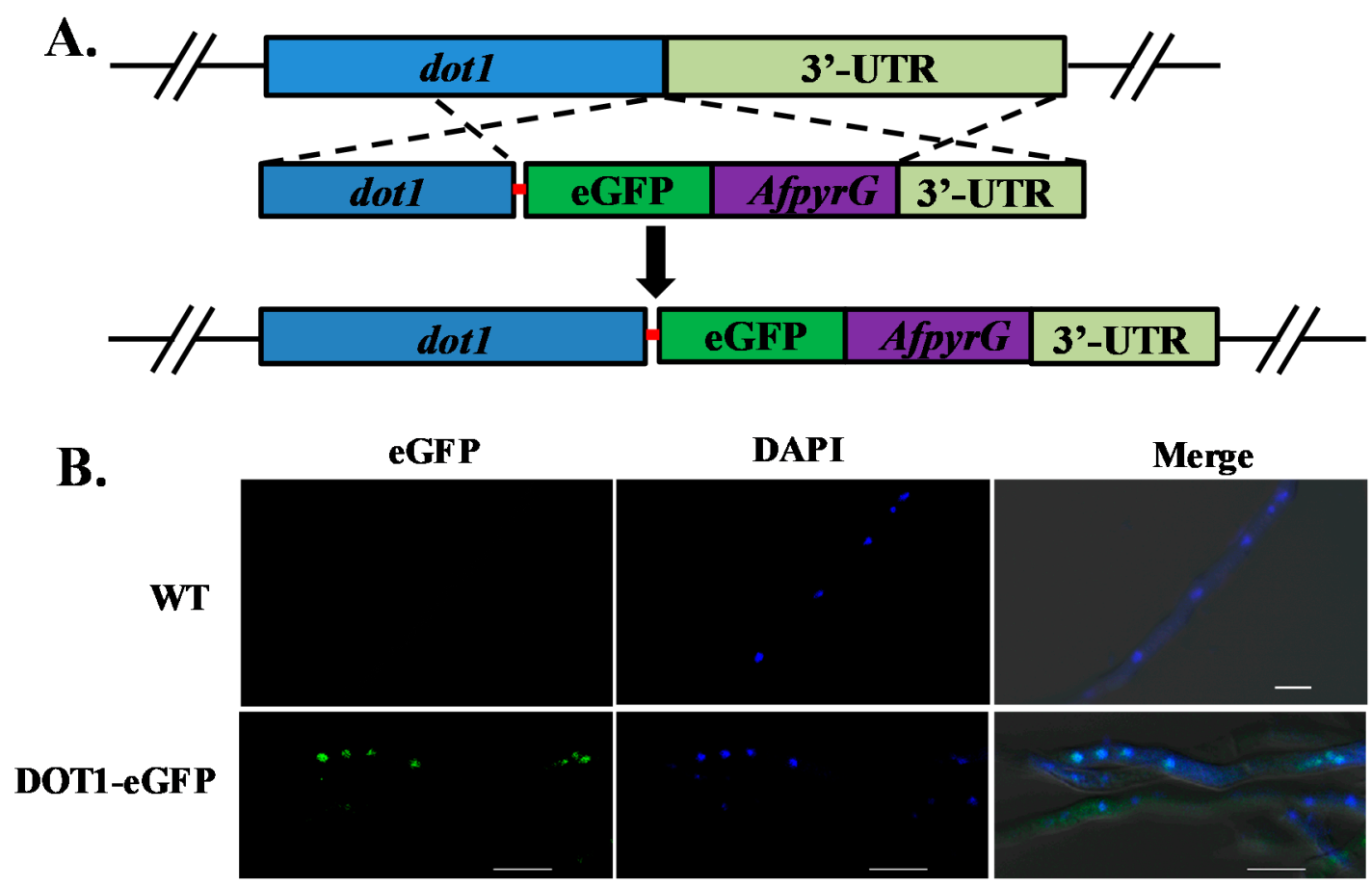

Figure 8. Location of Dot1-eGFP in A. flavus. (A) Construction strategy of $\operatorname{dot} 1(p)$-dot1-egfp strain. A 5 Gly-Ala linker was shown as a red line. (B) Fluorescent image of Dot1-eGFP during the hyphae growth period, the nucleus was stained by 40, 6-diamidino-2-phenylindole (DAPI).

\section{Discussion}

Histone methylation, as an important epigenetic modification, plays a vital role in the recruitment of other chromatin remodeling complexes and transcriptional machinery [16,29]. As an important HPTM, histone lysine methylation catalyzed by Dot1 is reported to be found from yeast to humans, which has been shown to be required for the DNA damage checkpoint [28,30,31]. However, studies of H3K79 methyltransferase in filamentous fungi are still rare, and no previous publications have yet reported the existence of these in Aspergillus. Here, we functionally characterized Dot1 in A. flavus, which shares a 33\% overall identity with yeast Dot1. The locations and paralogs of dot1 in Aspergillus genomes and the phylogenetic analysis of the Dot1 constructed in this study revealed that Dot1 was quite conserved in biological functions among Aspergillus.

Histone lysine methylation has been shown to provide an epigenetic layer for transcriptional regulation, and the methylation could lead to chromatin regions being active or repressive [12-15]. In this study, we found that disruption of the H3K79 methyltransferase gene dot1 reduced A. flavus conidiation through down-regulating the transcriptional levels of the key transcription factors BrlA and AbaA [32]. Conidiation and sclerotial formation have been shown to stay balanced in Aspergillus [1]. Here, we also found that inactivation of dot1 up-regulated the expression levels of the sclerotia-related genes $n s d C, n s d D$ and $s c l R$, as a result, increasing sclerotia reproduction. Sclerotia is considered to be 
a survival structure for adapting to stress environments, here we also found that the $\Delta$ dot 1 mutant showed less sensitivity to genotoxicity stress, cell wall-damaging agents and oxidative stress. All this suggested that methyltransferase Dot1 is involved in fungal development and stress response.

In A. flavus, an AF gene cluster has been shown to be located near the telomeres [19,20], which are associated with specific chromatin structures [19,21]. Our former studies had shown that DNA methyltransferase and histone acetylation contribute to AF biosynthesis in A. flavus [10,33], but not for arginine methyltransferase [25], which indicates that HPTMs are involved in the regulation of AF biosynthesis. HPTMs such as acetylation, methylation, and ubiquitination have been linked to transcriptional silencing in the telomere region. The inactivation of H3K79 methylation or $\mathrm{H} 3 \mathrm{~K} 4$ methylation is quite important for heterochromatin formation and the maintenance of the silencing regions of chromatin in budding yeast [21-23]. An abnormal expression of the H3K79 methyltransferase gene dot1 in yeast and mammalian cells leads to a decrease in gene silence [23,24]. Here, we found that the most important secondary metaboliteaflatoxin in A. flavus was severely impaired in the dot 1 deficient mutant compared to the WT strain. In A. nidulans, studies have shown that H3K9 methylation and heterochromatin protein-binding are involved in the activation of the sterigmatocystin gene cluster [34]. Simultaneously, we found that the transcription of genes relevant to aflatoxin biosynthesis, including the structural genes aflC and aflO and the regulator gene aflS, were prominently suppressed in the $\Delta$ dot1 mutant. However, the expression levels of the AF global regulator gene aflR showed no difference between the $\Delta$ dot 1 mutant and WT strain. Dot1 might affect AF biosynthesis by regulation of the activation of AflS, which could affect the activity of AflR in A. flavus. Therefore, it could be suggested that Dot1 is involved in activating the aflatoxin biosynthesis-relevant gene cluster.

In many plant pathogens, including Magnaporthe oryzae and Fusarium graminearum, the histone lysine methylation is known to function in fungal virulence $[35,36]$. Many seed crops, such as maize corn and peanuts, can be potentially colonized by A. flavus, which could sporulate on injured seeds and subsequently contaminate the hosts with aflatoxin. Here the $\operatorname{dot}^{C}$ complemented strain, although normal in its phenotype, had a defect in the activation of aflS and AF production during colonization, indicating that Dot1 in the complemented strain might not fully function. However, we found that the $\Delta$ dot1 mutant shows a significant reduction in pathogenicity in A. flavus. Although the physiological significance of these H3K79 methylation events remains unknown, the reduction of conidiation and aflatoxin biosynthesis as a result of the inactivation of Dot1 might be related to fungal virulence in A. flavus.

\section{Conclusions}

We identified a novel and functional methyltransferase Dot1 in A. flavus, and we found that Dot1 contributes to conidiation, AF metabolism and fungal virulence in A. flavus. Our preliminary results suggest valuable information that could advance our understanding of H3K79 methylation modification in the regulation of AF biosynthesis and fungal pathogenicity in A. flavus, and would provide a potential target for new control strategies of this fungal pathogen.

\section{Materials and Methods}

\subsection{Strain and Culture Conditions}

The A. flavus strains used in this study are listed in Table 1. Potato dextrose agar (PDA, BD Difco, Franklin, NJ, USA) was used for the growth and conidiation assays, supplemented with the appropriate amounts of uridine $(5 \mathrm{mM})$, uracil $(5 \mathrm{mM})$, or pyrithiamine $(100 \mathrm{ng} / \mathrm{mL})$ when necessary. The modified Wickerham medium (WKM) was used for the sclerotial production analysis [37]. After being grown for 7 days, the cultures in the WKM plates were washed with $70 \%$ ethanol to visualize sclerotia. PDA agar supplemented with $100 \mu \mathrm{g} / \mathrm{mL}$ sodium dodecyl sulfate (SDS), $2.0 \mathrm{mM} / \mathrm{L}$ tert-butyl hydroperoxide (tBooH), $15 \mathrm{mM}$ hydroxyurea (HU), or $0.02 \%$ methyl methanecsulfonate (MMS) were 
used to determine sensitivities to multiple stresses. All the experiments were performed with technical triplicates, and were repeated three times.

Table 1. A. flavus strains used in this study.

\begin{tabular}{ccc}
\hline Strain & Genotype Description & Reference \\
\hline A. flavus CA14 PTs & $\Delta k u 70, \Delta p y r G$ & {$[38]$} \\
wild-type & $\Delta k u 70, \Delta p y r G::$ AfpyrG & This study \\
$\Delta$ dot1 1 & $\Delta k u 70, \Delta \operatorname{dot} 1::$ AfpyrG & This study \\
$\Delta \operatorname{dot} 1^{C}$ & $\Delta k u 70, \Delta \operatorname{dot} 1::$ AfpyrG, dot1 $(p):: \operatorname{dot} 1:: p \operatorname{ptr} A$ & This study \\
Gdot 1 & $\Delta k u 70, \operatorname{dot} 1(p):: \operatorname{dot} 1-\operatorname{egfp}::$ AfpyrG & This study \\
\hline
\end{tabular}

\subsection{Generation of Gene Deletion and Complementation Strains}

The dot 1 deficient mutant $(\Delta \operatorname{dot} 1)$ and the $\Delta \operatorname{dot} 1$ complemented strain $\left(\operatorname{dot} 1^{C}\right)$ were generated by using a previously described method [33]. The primers used for gene knockout are listed in Table 2 . A 1189-bp 5' flanking fragment of dot 1 was amplified with primers dot1/P1 and dot1/P3, and a 1033-bp $3^{\prime}$ flanking fragment of dot 1 was amplified using primers dot1/P4 and dot1/P6. A pyrG selective marker was amplified from $A$. fumigatus genomic DNA with primers $p y r G / F$ and $p y r G / R$. The nested primers dot 1/P2 and dot1/P5 were used to generate the dot 1 deletion construct containing the $5^{\prime}$ and $3^{\prime}$ flanking region and the pyrG selection marker. The fusion PCR products were purified and transformed into the protoplasts of $A$. flavus CA14 PTs strain using an established procedure (Yang et al., 2016). Transformants were screened by PCR with primer dot1-ORF/F and dot1-ORF/R (Table 2), and further confirmed by Southern blot analysis.

Table 2. Primers used for gene deletion and complementation.

\begin{tabular}{|c|c|c|}
\hline Primers & Sequence $\left(5^{\prime}-3^{\prime}\right)$ & Application \\
\hline $\operatorname{dot} 1 / \mathrm{P} 1$ & CATTGAGATGGACGAGGACG & \multirow{8}{*}{ dot 1 deletion and probe } \\
\hline $\operatorname{dot}+1 / \mathrm{P} 3$ & GGGTGAAGAGCATTGTTTGAGGCGT & \\
\hline $\operatorname{dot} 1 / \mathrm{P3}$ & TGACCGAGCGGAAATGT & \\
\hline \multirow{2}{*}{$\operatorname{dot} 1 / \mathrm{P} 4$} & GCATCAGTGCCTCCTCTCAGACCA & \\
\hline & CTACGCGGTTACCGAGAC & \\
\hline $\operatorname{dot} 1 / \mathrm{P} 6$ & CGACAGAAAGCCATAATGAAAT & \\
\hline $\operatorname{dot} 1 / \mathrm{P} 2$ & CGAGGACGACAATGACTACAC & \\
\hline $\operatorname{dot} 1 / \mathrm{P} 5$ & GAGTTGAAGGGAAAGGCTAAA & \\
\hline PyrG/F & GCСТCAAACAATGCTCTTCACCC & \multirow{3}{*}{ pyrG selective marker } \\
\hline PyrG/R & GTCTGAGAGGAGGCACTGATGC & \\
\hline P801/R & CAGGAGTTCTCGGGTTGTCG & \\
\hline \multirow{2}{*}{$\begin{array}{l}\operatorname{dot} 1-\mathrm{ORF} / \mathrm{F} \\
\operatorname{dot} 1-\mathrm{ORF} / \mathrm{R}\end{array}$} & TTCTTACAGTATCCGAGTGC & \multirow{2}{*}{ dot1 mutant screen } \\
\hline & TTCATGTCCAGGAAGTGGTT & \\
\hline \multirow{2}{*}{$\mathrm{CM}-\operatorname{dot} 1 / \mathrm{F}$} & CTATGACCATGATTACGCCAACTATGACCATG & \multirow{4}{*}{$\begin{array}{l}\text { dot1 complementation } \\
\text { construct }\end{array}$} \\
\hline & ATTACGCCAAGCTTAGCCTAAGCAGCAGGTGAAGC & \\
\hline \multirow{2}{*}{$\mathrm{CM}-\operatorname{dot} 1 / \mathrm{R}$} & CCAGTGAATTCGAGCTCGGTACCG & \\
\hline & ATGGCAAGGATGGGCAAAG & \\
\hline \multirow{2}{*}{ eGFP-pyrG/F } & GGAGCTGGTGCAGGCGCTGGAGCCGGT & \multirow{4}{*}{$e g f p$} \\
\hline & GCCATGGTGAGCAAGGGCGAGGA & \\
\hline \multirow{2}{*}{ eGFP-pyrG/R } & GGGTGAAGAGCATTGTTTGAGGC & \\
\hline & TTACTTGTACAGCTCGTCCATG & \\
\hline dot1-eGFP/P1 & ATTCTTACAGTATCCGAGTGC & \multirow{4}{*}{ dot1-gfp tag construct } \\
\hline \multirow{3}{*}{$\begin{array}{l}\text { dot1-eGFP/P3 } \\
\operatorname{dot} 1-\mathrm{eGFP} / \mathrm{P} 2\end{array}$} & GGCTCCAGCGCCTGCACCA & \\
\hline & GCTCCACCCATGCTCTCTGCAAAAG & \\
\hline & AAAATTACATACCGGAGGACG & \\
\hline
\end{tabular}

To complete $\Delta d o t 1$, a $2.9-\mathrm{kb}$ PCR product (1.6-kb dot1 coding sequence, $0.8-\mathrm{kb}$ upstream sequence and $0.5-\mathrm{kb}$ dot 1 terminator region) was amplified from $A$. flavus wild-type genomic DNA using primers $\operatorname{dot} 1 \mathrm{CM} / \mathrm{F}$ and $\operatorname{dot} 1 \mathrm{CM} / \mathrm{R}$. The purified PCR product and the linearization pPTRI (Takara, Tokyo, 
Japan) vector were then recombined with T4 DNA ligase. The recombinant pPTR-dot 1 was transformed into $\Delta$ dot 1 protoplasts. The pyrithiamine-resistant transformants were screened by $\mathrm{PCR}$, and confirmed by reverse transcription PCR (RT-PCR).

\subsection{Aflatoxin Analysis}

The WT, $\Delta$ dot 1 and dot1C strains were incubated into $20 \mathrm{~mL}$ potato dextrose broth (PDB) medium in the dark at $29^{\circ} \mathrm{C}$ for 5 days. Then the cultures were used for AF extraction. AF extraction was performed as previously described in [33]. Thin layer chromatography (TLC) and high performance liquid chromatography (HPLC) were both used to measure AF production with the method described in [33].

\subsection{Maize Corn Infection Assay}

The maize seed colonization assay was performed as described previously in [6,39]. The maize seeds were co-cultured with conidia of the WT, $\Delta \operatorname{dot} 1$ and $\operatorname{dot} 1^{\mathrm{C}}$ strains $29^{\circ} \mathrm{C}$ for $5 \mathrm{~d}$. After five days incubation, the infected seeds were collected in $50 \mathrm{~mL}$ Falcon tubes, then mixed with $15 \mathrm{~mL}$ of sterile $0.05 \%$ Tween 80 , followed by 2 min vortex to release the spores. A $100 \mu \mathrm{L}$ aliquot of spores was removed, diluted, and counted haemocytometrically. $15 \mathrm{~mL}$ of chloroform were added to the Falcon tubes, and the tubes were shaken at $29^{\circ} \mathrm{C}$ for $30 \mathrm{~min} .10 \mathrm{~mL}$ of the organic layer was removed, dried down, and resuspended in $1 \mathrm{~mL}$ chloroform. Finally, AF production was detected by TLC.

\subsection{Gene Expression Detection}

The gene expression level was detected by qRT-PCR. $48 \mathrm{~h}$ old mycelia of $A$. flavus were collected, washed, and lyophilized from PDA medium. Total RNA was isolated according to the protocol previously described by Yang et al. [6]. SYBR Green Supermix (Takara) was used for the qRT-PCR reaction with the PikoReal 96 Real-time PCR system. The $2^{-\Delta \Delta C T}$ method was used to calcite the relative quantification of each transcript [40]. The qRT-PCR primers are listed in Table 3.

Table 3. Primers used for RT-PCR.

\begin{tabular}{|c|c|c|}
\hline Primers & Sequence $\left(5^{\prime}-3^{\prime}\right)$ & Application \\
\hline brlA/QF & GCCTCCAGCGTCAACCTTC & \multirow{2}{*}{ brlA qRT-PCR } \\
\hline brlA/QR & TCTCTTCAAATGCTCTTGCСТC & \\
\hline$a b a A / Q F$ & CACGGAAATCGCCAAAGAC & \multirow{2}{*}{$a b a A$ qRT-PCR } \\
\hline$a b a A / Q R$ & TGCCGGAATTGCCAAAG & \\
\hline$n s d C / Q F$ & GCCAGACTTGCCAATCAC & \multirow{2}{*}{$n s d C$ qRT-PCR } \\
\hline$n s d C / Q R$ & CATCCACCTTGCCCTTTA & \\
\hline$n s d D / Q F$ & GGACTTGCGGGTCGTGCTA & \multirow{2}{*}{$n s d D$ qRT-PCR } \\
\hline$n s d D / Q R$ & AGAACGCTGGGTCTGGTGC & \\
\hline$s c l R / Q F$ & CAATGAGCCTATGGGAGTGG & \multirow{2}{*}{ sclR qRT-PCR } \\
\hline$s c l R / Q R$ & ATCTTCGCCCGAGTGGTT & \\
\hline aflC/QF & GTGGTGGTTGCCAATGCG & \multirow{2}{*}{ aflC qRT-PCR } \\
\hline aflC/QR & CTGAAACAGTAGGACGGGAGC & \\
\hline aflR/QF & AAAGCACССТGTCTTCССТAAC & \multirow{2}{*}{ aflR qRT-PCR } \\
\hline aflR/QR & GAAGAGGTGGGTCAGTGTTTGTAG & \\
\hline aflS/QF & CGAGTCGCTCAGGCGCTCAA & \multirow{2}{*}{ aflS qRT-PCR } \\
\hline aflS /QR & GCTCAGACTGACCGCCGCTC & \\
\hline aflO/QF & GATTGGGATGTGGTCATGCGATT & \multirow{2}{*}{ aflO qRT-PCR } \\
\hline aflO/QR & GCCTGGGTCCGAAGAATGC & \\
\hline Actin/QF & ACGGTGTCGTCACAAACTGG & \multirow{2}{*}{ actin qRT-PCR } \\
\hline Actin/QR & CGGTTGGACTTAGGGTTGATAG & \\
\hline
\end{tabular}




\subsection{Generation of Dot1-eGFP Strain}

The former approach for protein location was performed to generate the Dot1-GFP strain $[6,41]$. To generate the dot1-eGFP construct, a 1068 bp dot1 ORF without the termination codon (TAG) and a 1033-bp $3^{\prime}$ flanking fragment of dot1 was amplified from A. flavus WT strain gDNA using the primer pairs dot1-eGFP, P1-dot1-eGFP/P3 and dot1/P4, dot1/P6, respectively. The primers dot1-eGFP/P2 and dot1-eGFP/P5 were used to generate the Dot1-eGFP fusion PCR cassettes containing the upstream and downstream region, egfp and the $p y r G$ selection marker. The purified fusion PCR products were inserted into the protoplasts of the A. flavus CA14 PTs strain, and the selected transformants were then confirmed by PCR.

\subsection{Microscopic Determination of Dot1-eGFP Location}

To assay the subcellular location pattern of Dot1-eGFP, $12 \mathrm{~h}$ growth mycelial was collected and analyzed using a Leica SP8 confocal laser scanning microscope. Dual-channel imaging was used to sequentially image cells labeled with DAPI (excitation: $405 \mathrm{~nm}$, emission bandwidth: $420-460 \mathrm{~nm}$ ), and eGFP (excitation: $488 \mathrm{~nm}$, emission bandwidth: 525/565 nm).

\subsection{Statistical Analysis}

Statistical analysis was performed using ANOVA and least significant difference (LSD) tests to determine significant differences among group means. A $p$-values less than 0.05 was regarded as statistically significant.

Acknowledgments: Funding was provided for this research from (No. 2013CB127802), the grants of the National Natural Science Foundation of China (No. 31172297). We especially thanked Dr Perng Kuang Chang (Southern Regional Research Center, United States Department of Agriculture, New Orleans, USA), Prof. Yang Liu (Institute of Food Science and Technology CAAS), Prof. Kong Qing for their kindness to provide the strains. We thanked Dr. Yanyun Li (FAFU, Life Science College) for her help in taking the confocal images. We thanked Center for Molecular Cell and Systems Biology, Life Science College of FAFU, for providing facilities and support.

Author Contributions: Kunlong Yang and Shihua Wang designed the experiments and wrote the manuscript. Linlin Liang, Yinghang Liu and Kunlong Yang performed all the experiments. Guinan Lin, Zhangling Xu, Huahui Lan and Xiuna Wang performed a few experiments and data analysis. All authors read and approved the final manuscript.

Conflicts of Interest: The authors report no conflicts of interest. The authors alone are responsible for the content and writing of the paper.

\section{References}

1. Amaike, S.; Keller, N.P. Aspergillus flavus. Ann. Rev. Phytopathol. 2011, 49, 107-133. [CrossRef] [PubMed]

2. Yang, K.; Zhuang, Z.; Zhang, F.; Song, F.; Zhong, H.; Ran, F.; Yu, S.; Xu, G.; Lan, F.; Wang, S. Inhibition of aflatoxin metabolism and growth of Aspergillus flavus in liquid culture by a DNA methylation inhibitor. Food Addit. Contam. Part A Chem. Anal. Control Expo. Risk Assess. 2015, 32, 554-563. [CrossRef] [PubMed]

3. Abbas, H.K.; Shier, W.T.; Plasencia, J.; Weaver, M.A.; Bellaloui, N.; Kotowicz, J.K.; Butler, A.M.; Accinelli, C.; de la Torre-Hernandez, M.E.; Zablotowicz, R.M. Mycotoxin contamination in corn smut (ustilago maydis) galls in the field and in the commercial food products. Food Control 2017, 71, 57-63. [CrossRef]

4. Hedayati, M.T.; Pasqualotto, A.C.; Warn, P.A.; Bowyer, P.; Denning, D.W. Aspergillus flavus: Human pathogen, allergen and mycotoxin producer. Microbiology 2007, 153, 1677-1692. [CrossRef] [PubMed]

5. Nie, X.; Yu, S.; Qiu, M.; Wang, X.; Wang, Y.; Bai, Y.; Zhang, F.; Wang, S. Aspergillus flavus sumo contributes to fungal virulence and toxin attributes. J. Agric. Food Chem. 2016, 64, 6772-6782. [CrossRef] [PubMed]

6. Yang, K.; Liu, Y.; Liang, L.; Li, Z.; Qin, Q.; Nie, X.; Wang, S. The high-affinity phosphodiesterase pdeh regulates development and aflatoxin biosynthesis in Aspergillus flavus. Fungal Genet. Biol. FG B 2017, 101, 7-19. [CrossRef] [PubMed]

7. Chalivendra, S.C.; DeRobertis, C.; Chang, P.K.; Damann, K.E. Cyclopiazonic acid is a pathogenicity factor for Aspergillus flavus and a promising target for screening germplasm for ear rot resistance. Mol. Plant Microbe Interact. MPMI 2017, 30, 361-373. [CrossRef] [PubMed] 
8. Bosso, L.; Lacatena, F.; Varlese, R.; Nocerino, S.; Cristinzio, G.; Russo, D. Plant pathogens but not antagonists change in soil fungal communities across a land abandonment gradient in a mediterranean landscape. Acta Oecol. 2017, 78, 1-6. [CrossRef]

9. Gacek-Matthews, A.; Berger, $\mathrm{H}$. Kdmb, a jumonji histone h3 demethylase, regulates genome-wide h3k4 trimethylation and is required for normal induction of secondary metabolism in aspergillus nidulans. PLoS Genet. 2016, 12, e1006222. [CrossRef] [PubMed]

10. Lan, H.; Sun, R.; Fan, K.; Yang, K.; Zhang, F.; Nie, X.Y.; Wang, X.; Zhuang, Z.; Wang, S. The Aspergillus flavus histone acetyltransferase aflgcne regulates morphogenesis, aflatoxin biosynthesis, and pathogenicity. Front. Microbiol. 2016, 7, 1324. [CrossRef] [PubMed]

11. Macheleidt, J.; Mattern, D.J.; Fischer, J.; Netzker, T.; Weber, J.; Schroeckh, V.; Valiante, V.; Brakhage, A.A. Regulation and role of fungal secondary metabolites. Annu. Rev. Genet. 2016, 50, 371-392. [CrossRef] [PubMed]

12. Connolly, L.R.; Smith, K.M.; Freitag, M. The fusarium graminearum histone h3 k27 methyltransferase kmt6 regulates development and expression of secondary metabolite gene clusters. PLoS Genet. 2013, 9, e1003916. [CrossRef] [PubMed]

13. Mikkelsen, T.S.; Ku, M.; Jaffe, D.B.; Issac, B.; Lieberman, E.; Giannoukos, G.; Alvarez, P.; Brockman, W.; Kim, T.K.; Koche, R.P.; et al. Genome-wide maps of chromatin state in pluripotent and lineage-committed cells. Nature 2007, 448, 553-560. [CrossRef] [PubMed]

14. Brakhage, A.A. Regulation of fungal secondary metabolism. Nat. Rev. Microbiol. 2013, 11, 21-32. [CrossRef] [PubMed]

15. Gacek, A.; Strauss, J. The chromatin code of fungal secondary metabolite gene clusters. Appl. Microbiol. Biotechnol. 2012, 95, 1389-1404. [CrossRef] [PubMed]

16. Strauss, J.; Reyes-Dominguez, Y. Regulation of secondary metabolism by chromatin structure and epigenetic codes. Fungal Genet. Biol. FG B 2011, 48, 62-69. [CrossRef] [PubMed]

17. Lewis, Z.A.; Honda, S.; Khlafallah, T.K.; Jeffress, J.K.; Freitag, M.; Mohn, F.; Schubeler, D.; Selker, E.U. Relics of repeat-induced point mutation direct heterochromatin formation in neurospora crassa. Genome Res. 2009, 19, 427-437. [CrossRef] [PubMed]

18. Adhvaryu, K.K.; Morris, S.A.; Strahl, B.D.; Selker, E.U. Methylation of histone h3 lysine 36 is required for normal development in neurospora crassa. Eukaryot. Cell 2005, 4, 1455-1464. [CrossRef] [PubMed]

19. Palmer, J.M.; Mallaredy, S.; Perry, D.W.; Sanchez, J.F.; Theisen, J.M.; Szewczyk, E.; Oakley, B.R.; Wang, C.C.; Keller, N.P.; Mirabito, P.M. Telomere position effect is regulated by heterochromatin-associated proteins and nkua in aspergillus nidulans. Microbiology 2010, 156, 3522-3531. [CrossRef] [PubMed]

20. Keller, N.P.; Turner, G.; Bennett, J.W. Fungal secondary metabolism—from biochemistry to genomics. Nat. Rev. Microbiol. 2005, 3, 937-947. [CrossRef] [PubMed]

21. Takahashi, Y.H.; Schulze, J.M.; Jackson, J.; Hentrich, T.; Seidel, C.; Jaspersen, S.L.; Kobor, M.S.; Shilatifard, A. Dot1 and histone h3k79 methylation in natural telomeric and hm silencing. Mol. Cell 2011, 42, 118-126. [CrossRef] [PubMed]

22. Osborne, E.A.; Dudoit, S.; Rine, J. The establishment of gene silencing at single-cell resolution. Nat. Genet. 2009, 41, 800-806. [CrossRef] [PubMed]

23. Lacoste, N.; Utley, R.T.; Hunter, J.M.; Poirier, G.G.; Cote, J. Disruptor of telomeric silencing-1 is a chromatin-specific histone h3 methyltransferase. J. Biol. Chem. 2002, 277, 30421-30424. [CrossRef] [PubMed]

24. Ng, H.H.; Feng, Q.; Wang, H.; Erdjument-Bromage, H.; Tempst, P.; Zhang, Y.; Struhl, K. Lysine methylation within the globular domain of histone $\mathrm{h} 3$ by dot1 is important for telomeric silencing and sir protein association. Genes Dev. 2002, 16, 1518-1527. [CrossRef] [PubMed]

25. Li, Y.; He, Y.; Li, X.; Fasoyin, O.E.; Hu, Y.; Liu, Y.; Yuan, J.; Zhuang, Z.; Wang, S. Histone methyltransferase aflrmta gene is involved in the morphogenesis, mycotoxin biosynthesis, and pathogenicity of Aspergillus flavus. Toxicon 2017, 127, 112-121. [CrossRef] [PubMed]

26. Gacek-Matthews, A.; Noble, L.M.; Gruber, C.; Berger, H.; Sulyok, M.; Marcos, A.T.; Strauss, J.; Andrianopoulos, A. Kdma, a histone $\mathrm{h} 3$ demethylase with bipartite function, differentially regulates primary and secondary metabolism in aspergillus nidulans. Mol. Microbiol. 2015, 96, 839-860. [CrossRef] [PubMed]

27. Govindaraghavan, M.; Anglin, S.L.; Osmani, A.H.; Osmani, S.A. The set1/compass histone h3 methyltransferase helps regulate mitosis with the cdk1 and nima mitotic kinases in aspergillus nidulans. Genetics 2014, 197, 1225-1236. [CrossRef] [PubMed] 
28. Rossodivita, A.A.; Boudoures, A.L.; Mecoli, J.P.; Steenkiste, E.M.; Karl, A.L.; Vines, E.M.; Cole, A.M.; Ansbro, M.R.; Thompson, J.S. Histone h3 k79 methylation states play distinct roles in uv-induced sister chromatid exchange and cell cycle checkpoint arrest in saccharomyces cerevisiae. Nucleic Acids Res. 2014, 42, 6286-6299. [CrossRef] [PubMed]

29. Croken, M.M.; Nardelli, S.C.; Kim, K. Chromatin modifications, epigenetics, and how protozoan parasites regulate their lives. Trends Parasitol. 2012, 28, 202-213. [CrossRef] [PubMed]

30. Ontoso, D.; Acosta, I.; van Leeuwen, F.; Freire, R.; San-Segundo, P.A. Dot1-dependent histone h3k79 methylation promotes activation of the mek1 meiotic checkpoint effector kinase by regulating the hop1 adaptor. PLoS Genet. 2013, 9, e1003262. [CrossRef] [PubMed]

31. Bani Ismail, M.; Shinohara, M.; Shinohara, A. Dot1-dependent histone h3k79 methylation promotes the formation of meiotic double-strand breaks in the absence of histone $\mathrm{h} 3 \mathrm{k} 4$ methylation in budding yeast. PLoS ONE 2014, 9, e96648. [CrossRef] [PubMed]

32. Han, S.; Adams, T.H. Complex control of the developmental regulatory locus brla in aspergillus nidulans. Mol. Genet. Genom. MGG 2001, 266, 260-270.

33. Yang, K.; Liang, L.; Ran, F.; Liu, Y.; Li, Z.; Lan, H.; Gao, P.; Zhuang, Z.; Zhang, F.; Nie, X.; et al. The dmta methyltransferase contributes to Aspergillus flavus conidiation, sclerotial production, aflatoxin biosynthesis and virulence. Sci. Rep. 2016, 6, 23259. [CrossRef] [PubMed]

34. Reyes-Dominguez, Y.; Bok, J.W.; Berger, H.; Shwab, E.K.; Basheer, A.; Gallmetzer, A.; Scazzocchio, C.; Keller, N.; Strauss, J. Heterochromatic marks are associated with the repression of secondary metabolism clusters in aspergillus nidulans. Mol. Microbiol. 2010, 76, 1376-1386. [CrossRef] [PubMed]

35. Pham, K.T.; Inoue, Y.; Vu, B.V.; Nguyen, H.H.; Nakayashiki, T.; Ikeda, K.; Nakayashiki, H. Moset1 (histone h3k4 methyltransferase in magnaporthe oryzae) regulates global gene expression during infection-related morphogenesis. PLoS Genet. 2015, 11, e1005385.

36. Liu, Y.; Liu, N.; Yin, Y.; Chen, Y.; Jiang, J.; Ma, Z. Histone h3k4 methylation regulates hyphal growth, secondary metabolism and multiple stress responses in fusarium graminearum. Environ. Microbiol. 2015, 17, 4615-4630. [CrossRef] [PubMed]

37. Chang, P.K.; Scharfenstein, L.L.; Mack, B.; Ehrlich, K.C. Deletion of the Aspergillus flavus orthologue of a. Nidulans flug reduces conidiation and promotes production of sclerotia but does not abolish aflatoxin biosynthesis. Appl. Environ. Microbiol. 2012, 78, 7557-7563. [CrossRef] [PubMed]

38. Chang, P.K.; Scharfenstein, L.L.; Wei, Q.; Bhatnagar, D. Development and refinement of a high-efficiency gene-targeting system for Aspergillus flavus. J. Microbiol. Methods 2010, 81, 240-246. [CrossRef] [PubMed]

39. Tsitsigiannis, D.I.; Keller, N.P. Oxylipins act as determinants of natural product biosynthesis and seed colonization in aspergillus nidulans. Mol. Microbiol. 2006, 59, 882-892. [CrossRef] [PubMed]

40. Livak, K.J.; Schmittgen, T.D. Analysis of relative gene expression data using real-time quantitative pcr and the 2(-delta delta $\mathrm{c}(\mathrm{t}))$ method. Methods 2001, 25, 402-408. [CrossRef] [PubMed]

41. Yang, K.; Qin, Q.; Liu, Y.; Zhang, L.; Liang, L.; Lan, H.; Chen, C.; You, Y.; Zhang, F.; Wang, S. Adenylate cyclase acya regulates development, aflatoxin biosynthesis and fungal virulence in Aspergillus flavus. Front. Cell. Infect. Microbiol. 2016, 6, 190. [CrossRef] [PubMed]

(C) 2017 by the authors. Licensee MDPI, Basel, Switzerland. This article is an open access article distributed under the terms and conditions of the Creative Commons Attribution (CC BY) license (http:// creativecommons.org/licenses/by/4.0/). 